\title{
Foreign direct investment and cost uncertainty: Correlation and learning effects
}

\author{
Anthony Creane ${ }^{\dagger}$ and Kaz Miyagiwa ${ }^{\ddagger} \$$
}

\begin{abstract}
We examine a foreign firm's choice between exporting and foreign direct investment (FDI) under country-specific cost uncertainty. Unlike exporting, FDI exposes foreign and home firms to common shocks. This results in a correlation of strategies, harming the firms. However, the exposure to common shocks also benefits the firms by enabling them to learn each other's cost realization. The net effect is negative, implying that country-specific cost uncertainty forms a barrier to FDI. The foreign firm, then, chooses exporting unless FDI gives it a substantial cost advantage. Therefore, when FDI actually occurs, the home firm is hurt but consumers always benefit.
\end{abstract}

JEL: D83, F12

Key words: information, FDI, access mode selection, cost uncertainty, globalization

${ }^{\dagger}$ Michigan State University

${ }^{\ddagger}$ ISER, Osaka University, and Emory University

$\S$ We thank Carl Davidson, Steve Matusz and participants at the Midwest International Economics meetings (2006) for their comments on preliminary work.

Corresponding Author: Kaz Miyagiwa, The Institute of Social and Economic Research, Osaka University, Mihogaoka, Ibaraki, Osaka 567-0047, Japan. E-mail: kmiyagiwa@gmail.com 


\section{Introduction}

International economists traditionally viewed foreign investment as an instance of international factor movement in general equilibrium competitive models, where capital crossed national borders in search of higher returns. However, the impressive rise in multinational activity during the last quarter-century has fundamentally changed the way economists think of foreign investment. ${ }^{1}$ The new view first emphasized advantages multinational enterprises have over local firms such as firm-level and plant-level scale economies as the cause of foreign direct investment (FDI). ${ }^{2}$ Later work subscribed to a relative-costs approach, according to which a firm's choice between exporting and FDI depends on the tradeoff between the setup cost and the trade costs (transportation cost and tariff charges) the firm can save with FDI. ${ }^{3}$

Most of this literature analyzes a firm's choice between exporting and FDI in a nonstochastic environment. Our aim here is to examine how uncertainty affects a firm's location choice in a strategic environment. In particular, we focus on country-specific cost (or productivity) uncertainty. Although country-specific cost and productivity shocks have been studied extensively in the international macroeconomic literature, they remain unexplored in the context of international oligopoly, where location choice has strategic implications.

Consider a foreign firm serving buyers in the home country. Whether it builds a factory in the home country or the foreign country, the firm will face local economic shocks specific to the country where it locates production operations. ${ }^{4}$ Cost shocks may come from local sources such as labor union activities and expansions of the local economy, but even international shocks such as oil crises may also affect the firm's costs differently depending on its location as some countries handle the

\footnotetext{
${ }^{1}$ For reviews of this literature, see Caves (1991) and Markusen (1995, 2003).

${ }^{2}$ See, e.g., Helpman (1984) and Markusen (1984). Ethier (1986) was the first to emphasize the firm's internalization problem, which others took for granted.

${ }^{3}$ E.g., Horstmann and Markusen (1992) and Helpman, Melitz and Yeaple (2004).

${ }^{4}$ Note whether it is Brownfield or Greenfield FDI will have the same implications.
} 
shocks better than others.

If there is an indigenous rival, then there can be strategic effects from the shocks. To begin with, if the firms produce in separate countries they each are subject to their own country-specific cost shocks, which are unlikely to be perfectly correlated. In contrast, if the foreign firm locates in the home country both firms face the same country-specific shocks. The exposure to the common cost shocks can affect the foreign firm's expected profit in two ways. First, it introduces a correlation into the firms' strategies. For example, if the rival faces a high cost and contracts output, the foreign firm's instinct would be to increase its output. When it produces there, however, the foreign firm faces the same high cost, and it too is forced to contract output. Second, it enables the firms to infer each other's cost realization by observing their own. ${ }^{5}$ If the rival faces a high cost, for example, the firm knows it from having itself drawn the high cost. Other actions the firms take, e.g., using common suppliers, also facilitate this type of learning.

We emphasize that these are separate and independent effects. In particular, the first effect arises from FDI even if the firms know each other's cost realizations regardless of their locations. For this reason we call the first phenomenon the correlation effect, while the second is referred to as the learning effect. We also emphasize that the correlation effect arises from the strategic competition, not from risk aversion, as the firms are assumed risk-neutral.

To fix these ideas, we consider a foreign firm competing with a home firm in the home country, though the results can be applied to other settings. ${ }^{6}$ The firms are risk-neutral and play

\footnotetext{
${ }^{5}$ While we focus on country specific shocks, we can include additional idiosyncratic uncertainties which the rival could never learn, but adding these to the model would not change the results. To concentrate on the relationship between the correlation and learning effect, we restrict the learning to the country specific shocks. As we discuss below in more detail, this environment in which the distribution of the costs changes has not been examined before in the information sharing literature. In fact, as we show below, the results here often differ from what one would expect based on the results in the information sharing literature (in particular proposition 6 and its corollary).

${ }^{6}$ For example, we could apply the results to a North-South model in which two firms in a developed country choose between exporting and foreign investment in a less developed country that does not have a local firm.
} 
a three-stage game. First, the foreign firm chooses between exporting and FDI to serve home country buyers. Then nature chooses country-specific cost values and reveals them to the firms, depending on their plant location. To make the effects clear, these are the only shocks we consider here, although the results can be compared against a broad range of environments. ${ }^{7}$ Finally, the firms compete in the home market.

Our analysis shows that the correlation effect decreases the foreign firm's expected profit, implying that the foreign firm is less likely to choose FDI even if it lowers the foreign firm's expected cost. In this sense cost uncertainty introduces a bias against FDI. In contrast, the learning effect, when it is present, mitigates but fails to completely nullify the negative impact of correlation.

We then examine the effect on home country welfare. Key to understanding it is the finding that the correlation and the learning effect work on home country consumers differently than on firms. The correlation of strategies harms the firms but benefit consumers, whereas the learning effect benefits the firms but harms consumers. When both effects are present, consumers are harmed by FDI unless it is accompanied by substantial price decreases. However, when only the correlation effect is present, consumers can benefit from FDI even if it results in higher prices! Interestingly, though correlation and learning have different effects on consumers than it does on the foreign firm, when the foreign firm chooses FDI the consumers always benefit. Consumers benefit because the foreign firm chooses FDI only if FDI cuts the expected cost sufficiently, leading to a price cut which benefits the consumers.

Since the home consumers and firm have conflicting preferences, home country preferences are more complex. For example, even when the home country prefers FDI in the

\footnotetext{
${ }^{7}$ There are many natural extensions. In particular, a companion paper (Creane and Miyagiwa, 2007) investigates the effect of firms also being subject firm-specific (idiosyncratic) cost shocks.
} 
absence of uncertainty, its preference switches to exporting as variance of country-specific cost increases.

It is worthwhile to emphasize that the effects here are driven by strategic competition and not by risk aversion. Indeed, there is a vast literature on the effects of risk aversion on a firm's production location (e.g., Viaene and Zilcha 1998). In those models, the firms make output or price decisions before the shock occurs. Here, instead, we take the long-run view of firms which understand that there will be shocks they face and that they will be able respond to these shocks. Indeed, applying the intuition of risk aversion to our question could give a misleading answer. If correlation of strategies reduces the variability of the firms' choices, then a risk aversion intuition may lead one to think that the firms benefit from the correlation effect. However, here we are examining how firms react to these shocks, or the new information. More correlation implies a firm has less ability to exploit strategically its shock and hence firms can be harmed. ${ }^{8}$

The remainder of the paper is organized in five sections. Section 2 reviews the related literature. Section 3 sets up the model. Section 4 compares the foreign firm's incentive to engage in FDI when there are only correlation effects. This requires the assumption that firms when making their strategic choices know each other's country specific costs shock, even when they are located in separate countries. While this assumption allows us to isolate on the correlation effect, a plausible alternative assumption is that firms isolated in separate countries will not know each other's costs as well as when they produce in the same country. In Section 5 we consider this, which introduces a learning effect in addition to the correlation effect. Section 6 discusses home country welfare. Section 7 reviews the effects of having the firms compete in prices instead of quantities and Section 8 concludes.

\footnotetext{
${ }^{8}$ The use of correlated observations as a mechanism to infer information has been used extensively in the contracting/optimal regulation literature when there is incomplete information. In contrast, here all agents know the state once it is realized.
} 


\section{The literature}

Because of the role of uncertainty in determining FDI, this paper shares a common aspect to the strand of research investigating the effects of exchange-rate uncertainty, albeit in nonstrategic environment; see, e.g., Cushman (1985) and Goldberg and Kolstad (1995). Our setting is most similar to the one in Sung and Lapan (2000) where the firm is risk-neutral and makes production decisions after resolution of uncertainty. ${ }^{9}$ The focus there, however, is on how increases in the variance of the exchange rate affect a monopolist's optimal strategy by raising the expected profit of the foreign plant and the option value of building a second plant. ${ }^{10}$ As a result, they find that as the exchange rate variance increases, FDI is more likely to be chosen. Our focus instead is on how for given cost distributions (i.e., variances) in different countries, location correlates strategies and facilitates learning, both of which, to the best of our knowledge, have not been noticed in the FDI literature. Given the difference in the environments, it is not surprising to find the opposite "result" here: as cost variance increases, FDI is less likely to be chosen.

The learning aspect of our work is related to the recent work of Qiu and Zhou (2006) on international merger. In their model a foreign firm engages in Cournot competition with multiple home firms in the home country where there is demand uncertainty. Home firms always

\footnotetext{
${ }^{9}$ While mainly concerned with the monopoly firm, Sung and Lapan (2000) also shows how the monopoly with its first mover advantage can deter entry by building factories in both the foreign and home country (but only producing from the plant that the exchange rate realization makes more profitable). They show this can occur with a sufficiently large exchange rate variance. In contrast, we take as a given an oligopolistic market, rather than a monopoly one.

${ }^{10}$ In contrast, Goldberg and Kolstad (1995) assume that the firm chooses output before resolution of exchange rates uncertainty, and focus primarily on the effect of exchange rate uncertainty on the decision of a risk-averse firm (see also, e.g., Viaene and Zilcha 1998). It is interesting to note that they find that risk neutral firms are "indifferent regarding the location of production facilities" when "expected production costs are the same in domestic and foreign markets" while we find a strict preference.
} 
observe demand intercept before making output decisions but the foreign firm cannot unless it merges with a home firm. Merging and sharing demand information, which is common-valued, with the foreign firm reduces a home firm's profit but it increases the joint profit of the home firm and the foreign firm. This is surprising since normally a merger between two firms in an oligopoly is unprofitable (Salant et al. 1986). While the Qiu-Zhou model focuses on the foreign firm's learning of common valued information (demand), here the location decision determines whether the parameters are private valued (exporting) or common valued (FDI).

Our model is also related in its theoretical structure to those in the information sharing literature; e.g. Gal-Or (1985), Raith (1995) Vives (1990). However, one could draw erroneous conclusions if one attempted to apply the results in the information sharing to the model here, as there are critical differences in the theoretical structures. Specifically, the information-sharing literature takes as given both the distribution of the costs shocks, as well as the type of information the firms are to share (e.g., private value or public valued). ${ }^{11}$ In contrast, here the choice of plant location changes both the distribution of the cost shocks and the type of information confronting the firms (from private valued with exporting, to public valued with FDI). That is, we focus on the firms considering the implications of their costs or other shocks being more correlated without information sharing. To that extent, we decompose one of the effects from information sharing. ${ }^{12}$

\section{Basic environment}

Suppose that the foreign firm (firm $\mathrm{f}$ ) and the home firm (firm $\mathrm{h}$ ) compete in the home

\footnotetext{
${ }^{11}$ Specifically, whether firms would share information depends on whether it is private or public valued. As the type of information changes here, the previous results in the literature do not apply. Another difference is that that information sharing literature examines the firms' incentives to enter into long-term contracts to pool the information they will acquire. In contrast, here, when the learning effect is present in FDI, the learning is not mutually sought but is unilaterally imposed on the home firm by the foreign firm's decision.

${ }^{12}$ Following on footnote 3, greater correlation of costs has important effects in that literature. However, the effect is usually a result of learning (e.g., more that can be inferred about other firms). See, e.g., Fershtman and Judd (1986) or Gal-Or (1995). A different way of viewing the problem facing a firm in our model is how correlated would it like its costs to be with its rival. In the above papers, it would want it to be uncorrelated to gain informational rents.
} 
country market. Firm $i(=\mathrm{h}, \mathrm{f})$ faces inverse demand

$$
\mathrm{p}_{\mathrm{i}}=1-\mathrm{q}_{\mathrm{i}}-\delta \mathrm{q}_{\mathrm{k}},
$$

where $\delta \in[0,1]$ is a measure of product substitutability. The case in which $\delta=1$ corresponds to the classic Cournot model. The home firm is assumed always to produce in the home country, but the foreign firm may either produce and export from the foreign country or locate production in the home country to serve home buyers.

Production costs are linear with only a country-specific component. Let $c_{h}$ and $c_{f}$, respectively, denote the home and the foreign firm's marginal cost. By assumption the foreign firm's marginal cost depends on its production location, which, when necessary, we indicate by $\mathrm{c}_{\mathrm{f}}(\mathrm{F})$ and $c_{f}(H)$, where $F$ denotes the foreign country and $H$ the home country. Further, marginal costs are stochastic and distributed with known country-specific mean $\overline{c_{i}}$ and common variance $\sigma^{2}$. Note that $c_{\mathrm{f}}(\mathrm{H})=\mathrm{c}_{\mathrm{h}}$, that is, when it locates in the home country the foreign firms draw the same cost realization that the home firm does. The assumption of common variance across countries ensures that asymmetry in variance will not drive the foreign firm's location decision (as it can in Sung and Lapan 2000). As we want to focus on when both firms produce, it is assumed that the support for $\mathrm{c}_{\mathrm{i}}$ is sufficiently small to insure an interior solution for all realizations of $\mathrm{c}_{\mathrm{i}}$. The final assumption is that FDI requires no setup cost. ${ }^{13}$ This assumption, together with others, then imply that in the absence of uncertainty the foreign firm prefers FDI over exporting if and only if FDI (producing in the home country) lowers its expected cost; i.e., $\overline{\mathrm{c}_{\mathrm{h}}}=\overline{\mathrm{c}_{\mathrm{f}}}(\mathrm{H})<\overline{\mathrm{c}_{\mathrm{f}}}(\mathrm{F})$.

We model the interaction between the firms in three stages. In stage one, the foreign firm chooses its location choice to serve home country buyers. In stage two, nature draws values for

\footnotetext{
${ }^{13}$ Alternatively, one can assume that the foreign firm enters the market with a new plant either in the foreign country or in the home country, with identical setup cost.
} 
the firms' costs, which depend on their locations, and reveals those values to the firms. The exact information structure will be described shortly. In stage three the firms compete in the home market, given the foreign firm's location choice from stage one.

A critical question turns on the information flows between the countries. A natural assumption (as in Qiu and Zhou 2006) is that there are informational advantages with respect to location, i.e., one learns the local condition only by locating there. Specifically, when the firms produce in separate countries, firms observe the cost shock specific to the country in which they locate but not the rival's, whereas, when they located in the same country, the firms can infer the rival's cost shock from observation of there own. Now, however, imagine the situation in which there are already sufficient informational flows across countries so the firms observe all cost shocks, no matter where they are located. In such an integrated world, FDI induces a correlation in the firms' strategies without generating additional learning, the case that cannot occur in Qiu and Zhou (2006). Such a model is useful in isolating the correlations effect. We will therefore explore this case first.

\section{The correlation effect}

Suppose that information flows across nations are complete so that both firms learn all costs shocks, regardless of their locations. In such an environment, FDI does not induce any additional learning but it still causes a correlation of strategies.

\section{A The third stage}

We solve the model backwards beginning with stage 3 , where firms simultaneously set output. Since regardless of whether the foreign firm chose exporting or FDI in the first stage, the firms observe all cost realizations, the third-stage game is one of complete information. The 
Cournot-Nash equilibrium output for firm i $(=h, f)$ is

$$
\mathrm{q}_{\mathrm{i}}=\left[(2-\delta)-2 \mathrm{c}_{\mathrm{i}}+\delta \mathrm{c}_{\mathrm{k}}\right] / \Delta
$$

where $\mathrm{k} \neq \mathrm{i}$ and $\Delta \equiv 4-\delta^{2}$. If the foreign firm chose exporting, each firm's cost is independently drawn, so the profit to the foreign firm is

$$
\pi_{f}^{X}=\left[(2-\delta)-2 \mathrm{c}_{\mathrm{f}}+\delta \mathrm{c}_{\mathrm{h}}\right]^{2} / \Delta^{2}
$$

The profit to the home firm is found by exchanging the subscripts in (2). If the foreign firm chose FDI instead, both firms draw identical costs so setting $\mathrm{c}_{\mathrm{f}}=\mathrm{c}_{\mathrm{h}}$ in (2) yields the equilibrium output

$$
q_{\mathrm{i}}^{\mathrm{FDI}}=\left[1-2 \mathrm{c}_{\mathrm{h}}\right] /(2+\ldots)
$$

and the equilibrium profit

$$
\pi_{\mathrm{i}}^{\mathrm{FDI}}=\left[1-2 \mathrm{c}_{\mathrm{h}}\right]^{2} /(2+)^{2}
$$

In stage two Nature moves, revealing all the costs to both firms regardless of the locations chosen in stage 1 . We are ready to move to stage 1.

\section{B The location decision}

The foreign firm's location choice depends on its expected profits. We thus first calculate the expected profits. Taking expectations of (4) yields each firm's expected profit with FDI as follows:

$$
\mathrm{E}\left[\pi_{i}^{F D I}\right]=\pi_{\mathrm{i}}\left(\overline{\mathrm{c}}_{\mathrm{h}}, \overline{\mathrm{c}}_{\mathrm{h}}\right)+\sigma_{\mathrm{h}}{ }^{2} /(2+\delta)^{2}
$$

where

$$
\pi_{\mathrm{i}}\left(\overline{\mathrm{c}}_{\mathrm{h}}, \overline{\mathrm{c}}_{\mathrm{h}}\right) \equiv\left[1-\overline{\mathrm{c}}_{\mathrm{h}}\right]^{2} /\left(2+\_\right)^{2}
$$

is the mean profit to firm i. With exporting, taking expectation of (2) yields the expected profit to the foreign firm: 


$$
\mathrm{E}\left[\pi_{\mathrm{f}}^{\mathrm{X}}\right]=\pi_{\mathrm{f}}\left(\overline{\mathrm{c}}_{\mathrm{f}}, \overline{\mathrm{c}}_{h}\right)+4 \sigma_{\mathrm{f}}^{2} / \Delta^{2}+\delta^{2} \sigma_{\mathrm{h}}{ }^{2} / \Delta^{2}
$$

where

$$
\pi_{\mathrm{f}}\left(\overline{\mathrm{c}}_{\mathrm{f}}, \overline{\mathrm{c}}_{h}\right) \equiv\left[(2-\delta)-2 \overline{\mathrm{c}}_{\mathrm{f}}+\delta \overline{\mathrm{c}}_{\mathrm{h}}\right]^{2} / \Delta^{2}
$$

is the mean profit to the foreign firm. Interchanging the subscripts in the above expressions yields the home firm's counterpart. Note that we added a country subscript on the variance terms to make explicit the source of each variance term although $\sigma_{\mathrm{h}}^{2}=\sigma_{\mathrm{f}}^{2}=\sigma^{2}$ by assumption.

The foreign firm chooses FDI only if $\mathrm{E}\left[\pi_{\mathrm{f}}^{F D I}\right]>\mathrm{E}\left[\pi_{\mathrm{f}}^{X}\right]$. This condition simplifies, after manipulation, to

$$
\sigma^{2}<\left(\overline{\mathrm{c}}_{\mathrm{f}}-\overline{\mathrm{c}}_{\mathrm{h}}\right)\left[2-\overline{\mathrm{c}}_{\mathrm{f}}-_{-}+\overline{\mathrm{c}}_{\mathrm{h}}(-1)\right] /_{-} .
$$

The right-hand side of (7) is positive only if $\left(\overline{\mathrm{c}}_{\mathrm{f}}>\overline{\mathrm{c}}_{\mathrm{h}}\right) \cdot{ }^{14}$ This condition, therefore, is necessary but not sufficient for FDI to be chosen. We thus state

\section{Proposition 1: With only correlation effects:}

\section{A. The foreign firm may choose exporting over FDI even if FDI gives it an expected cost} advantage relative to exporting $\left(\overline{\mathrm{c}}_{\mathrm{f}}>\overline{\mathrm{c}}_{\mathrm{h}}\right)$.

\section{B. When the foreign firm chooses FDI the home firm is worse off.}

Proposition 1A contrasts with the case of zero variance, in which, as already noted, the foreign firm chooses exporting over FDI only if $\bar{c}_{h} \leq \bar{c}_{f}$, thereby implying that the presence of country-specific cost uncertainty serves as a barrier to FDI. To understand this result intuitively, note first that profits are convex in costs. Now, suppose that the firm has a lower-than-average cost

\footnotetext{
${ }^{14}$ Inequality (7) implies that we have the opposite of what Sung and Lapan (2000) find: here an increase in variance reduces the probability of FDI. As discussed in the introduction this is not surprising given both the different source of the uncertainty (cost instead of exchange rate) as well as the different market structure (duopoly instead of monopoly).
} 
shock and expands its output. With exporting the firms' cost shocks are independently drawn so the rival's optimal strategy is uncorrelated to the firm's. In contrast, with FDI, the rival also faces the same low cost and expands its output as well. This correlation in the firms' strategies correlated makes the profits less convex, harming the firms. It follows that the foreign firm will not engage in FDI unless it reduces the expected cost significantly. In other words, if FDI occurs it is accompanied by a significant fall in the price, hurting the home firm all the more.

Proposition 1B captures a new insight into why the home firm is against FDI. First, the home firm is harmed as its strategies get correlated to those of the foreign firm. In addition, since FDI occurs only if it lowers the foreign firm's expected cost, this further harms the home firm.

The above analysis proceeded in an environment in which the firms observed countryspecific cost shocks, no matter where they produced - the correlation effect. Such an environment may be attained in a perfectly integrated world economy. However, it may be more natural to assume that there is some asymmetry in information: while each firm knows its cost realization, it is less familiar with the shocks its rival faces. In that case, FDI gives rise to the learning effect; i.e., the exposure to the common cost shock enables the firms infer to each other's cost realization from observation of their own.

In contrast to the correlation effect, the effect of learning in oligopoly has been extensively studied in the "information-sharing" literature. It is well known that sharing firm-specific or privatevalued cost information is beneficial to firms that compete in quantities but sharing common-valued information is harmful to them. ${ }^{15}$ That result however stems partly from the assumption that the cost distributions are exogenous: sharing cost information with another firm does not change the firm's cost distribution. In contrast, here FDI does change cost distributions; with exporting the firms face

\footnotetext{
${ }^{15}$ As is also well known, this result is sensitive to the type of competition (Gal-or 1986 and Shapiro 1986) as well as the type of information (see, e.g., Vives 1984 and Gal-or 1985 for demand uncertainty). For an overview of how the results vary see, e.g., Creane (1998).
} 
independent cost distributions but with FDI they face the common cost shocks. Also, FDI transforms the cost information from being private-valued to being public-valued, while in the information sharing literature this characteristic is assumed fixed.

In short, learning the rival's cost through FDI entails these aspects of learning, and hence the standard result in the information-sharing literature does not serve well to ascertain the learning effect in our analysis. In particular, since the learning effect comprises these differing aspects of information (private-valued and common-valued), whether the learning effect works with or against the correlation effect is not immediately obvious. To ascertain the learning effect, we will examine, in the next section, the model in which firms do not learn each other's cost if the foreign firm chooses exporting.

\section{FDI with learning}

In this section we assume that the firms do not learn their rival's cost realizations when located in different countries. ${ }^{16}$ Hence, the third-stage game is one of incomplete information with exporting while it is a game of incomplete information with FDI. To derive the equilibrium we first characterize the third stage for all possible outcomes and then work back to each previous stage.

\section{A The third stage}

In the third stage each firm simultaneously sets output. In a game of incomplete information firm $i$ maximizes expected profit

$$
\mathrm{E}\left[\left(1-\mathrm{q}_{\mathrm{i}}-\delta \mathrm{q}_{\mathrm{k}}-\mathrm{c}_{\mathrm{i}}\right) \mathrm{q}_{\mathrm{i}}\right]
$$

The first-order condition can be arranged to yield firm $i$ 's best response

\footnotetext{
${ }^{16}$ This is consistent with the case in which the firms learn their rival's costs shocks with a lag, i.e., after the firms have made their production decisions.
} 


$$
\mathrm{q}_{\mathrm{i}}=\left[1-\mathrm{c}_{\mathrm{i}}-\delta \mathrm{E}\left(\mathrm{q}_{\mathrm{k}}\right)\right] / 2
$$

Note that firm $i$ 's output is linear in its own cost and firm $k$ 's output choice.

We next derive the equilibrium outputs and profits. If exporting is chosen, the foreign firm faces the unit cost $c_{f}=c_{f}(F)$ and the home firm $c_{h}$ and they do not learn each other's cost realization. The Bayesian-Nash equilibrium outputs and profits are straightforward to derive from (8):

$$
\begin{aligned}
& \left.\mathrm{q}_{\mathrm{h}}^{\mathrm{X}}=\left[(2-\delta)-2 \mathrm{c}_{\mathrm{h}}+\overline{\delta \mathrm{c}_{\mathrm{f}}}\right]\right] / \Delta+\delta^{2}\left[\mathrm{c}_{\mathrm{h}}-\overline{\mathrm{c}}_{\mathrm{h}}\right] / 2 \Delta \\
& \mathrm{q}_{\mathrm{f}}^{\mathrm{X}}=\left[(2-\delta)-2 \mathrm{c}_{\mathrm{f}}+\overline{\delta \mathrm{c}_{\mathrm{h}}}\right] / \Delta+\delta^{2}\left[\mathrm{c}_{\mathrm{f}}-\overline{\mathrm{c}}_{\mathrm{F}}\right] / 2 \Delta,
\end{aligned}
$$

where the superscript $\mathrm{X}$ denotes exporting, and, it is recalled, $\Delta \equiv 4-\delta^{2}$. Firm $i$, after setting its output, expects its third-stage profits to be (i.e., conditioned on its observation $\mathrm{c}_{\mathrm{i}}$ )

$$
\mathrm{E}_{\mathrm{c}_{\mathrm{i}}}\left[\pi_{i}^{X}\right]=\left[\mathrm{q}_{i}^{\mathrm{X}}\right]^{2}
$$

In contrast, with FDI the firms play a standard Cournot game, with the equilibrium profit already given in (4) in the previous section. This completely characterizes the third-stage games.

In stage two Nature moves, revealing country-specific cost information to the firms located in that country. We turn now to the first stage.

\section{B The access mode decision}

When the foreign firm chooses exporting over FDI, neither firm can react to the rival's cost realizations which it does not observe. Hence, the competitor's cost cannot introduce variance into the firm's profit. ${ }^{17}$ Taking expectation of (8) yields the foreign firm's expected profits

$$
\mathrm{E}\left[\pi_{\mathrm{f}}^{X}\right]=\pi_{\mathrm{f}}\left(\overline{\mathrm{c}}_{\mathrm{f}}, \overline{\mathrm{c}}_{\mathrm{f}}\right)+\sigma^{2} / 4
$$

\footnotetext{
${ }^{17}$ This is because the rival's cost enters the firm's profit function linearly.
} 
where

$$
\pi_{\mathrm{f}}\left(\overline{\mathrm{c}}_{\mathrm{f}}, \overline{\mathrm{c}}_{h}\right) \equiv\left[(2-\delta)-2 \bar{c}_{f}+\delta \bar{c}_{h}\right]^{2} / \Delta^{2}
$$

is the "mean profit" (i.e., the profit if variance equals zero) and the variance term corresponds to the distribution of $c_{f}$. By contrast, when the foreign firm chooses FDI, $c_{f}(H)=c_{h}$. The expected profit $\mathrm{E}\left[\pi_{i}^{F D I}\right]$ is the same as in the previous section and is given in (5).

The foreign firm chooses FDI only if $\mathrm{E}\left[\pi_{\mathrm{f}}^{F D I}\right]>\mathrm{E}\left[\pi_{\mathrm{f}}^{X}\right]$, or

$$
\sigma^{2}<16\left(\overline{\mathrm{c}}_{\mathrm{f}}-\overline{\mathrm{c}}_{\mathrm{h}}\right)\left[2-\overline{\mathrm{c}}_{\mathrm{f}}-_{-}+\overline{\mathrm{c}}_{\mathrm{h}}(-1)\right] /{ }_{-}\left(2-{ }_{-}\right)^{2}\left(4+\_\right) \text {and } \overline{\mathrm{c}}_{\mathrm{f}}>\overline{\mathrm{c}}_{\mathrm{h}},
$$

Note that

$$
16\left(\overline{\mathrm{c}}_{\mathrm{f}}-\overline{\mathrm{c}}_{\mathrm{h}}\right)\left[2-\overline{\mathrm{c}}_{\mathrm{f}}-_{-}+\overline{\mathrm{c}}_{\mathrm{h}}(-1)\right] /{ }_{-}\left(2-{ }_{-}\right)^{2}\left(4-\_\right)<\left(\overline{\mathrm{c}}_{\mathrm{f}}-\overline{\mathrm{c}}_{\mathrm{h}}\right)\left[2-\overline{\mathrm{c}}_{\mathrm{f}}-_{-}+\overline{\mathrm{c}}_{\mathrm{h}}(-1)\right] /{ }_{-},
$$

where the right hand side of the inequality is that appearing in (7). It follows that in the presence of learning effect the foreign firm is induced to choose FDI at a smaller variance than in its absence. Put differently, it is more likely to choose FDI even if it offers a smaller cost advantage relative to exporting. However, FDI still requires that $\bar{c}_{\mathrm{f}}>\overline{\mathrm{c}}_{\mathrm{h}}$. It follows from these that the learning effect is positive but not large enough to offset the negative effect on the foreign firm's profit from a correlation of strategies. Thus, country-specific cost uncertainty continues to be a barrier to FDI in the presence of the favorable learning effect. As a result, the foreign firm chooses FDI over exporting only if it reduces costs, which reduces the price and hurts the home firm.

We summarize all this in

\section{Proposition 2: With both correlation and learning effects:}

A. The learning effect is positive so that the foreign firm is more likely to choose FDI in the presence of the learning effect than in its absence.

B. The correlation effect dominates the learning effect so, when the foreign firm chooses FDI 
instead of exporting, the home firm's profit falls.

\section{Home country policy}

We next examine the effect on home country welfare, given by the sum of consumer surplus and profit to the home firm. The main focus is: when the firms' and the home-country government's preferences towards FDI diverge, and what type of government interventions can be inferred from it. To make comparisons possible we first introduce preferences that would generate the demand specified in the previous sections.

Assume that there is a continuum of identical home country consumers with separable, linear utility in the numeraire good and quasiconcave preferences for the differentiated goods.

For the demand specified in quantity competition this implies that for the differentiated good utility is represented by the quadratic function

$$
\mathrm{U}\left(\mathrm{q}_{\mathrm{h}}, \mathrm{q}_{\mathrm{f}}\right)=\left(\mathrm{q}_{\mathrm{h}}+\mathrm{q}_{\mathrm{f}}\right)-(1 / 2)\left(\mathrm{q}_{\mathrm{h}}{ }^{2}+2 \delta \mathrm{q}_{\mathrm{h}} \mathrm{q}_{\mathrm{f}}+\mathrm{q}_{\mathrm{f}}{ }^{2}\right), \quad 1 \geq \delta>0 .
$$

Hence, welfare is

$$
\mathrm{W}\left(\mathrm{q}_{\mathrm{h}}, \mathrm{q}_{\mathrm{f}}\right)=\mathrm{U}\left(\mathrm{q}_{\mathrm{h}}, \mathrm{q}_{\mathrm{f}}\right)-\mathrm{p}_{\mathrm{h}} \mathrm{q}_{\mathrm{h}}-\mathrm{p}_{\mathrm{f}} \mathrm{q}_{\mathrm{f}}+\pi_{\mathrm{h}} .
$$

Using the consumer's first-order conditions (i.e., the inverse demand facing each firm), consumer surplus is

$$
\operatorname{CS}\left(\mathrm{q}_{\mathrm{h}}, \mathrm{q}_{\mathrm{f}}\right)=\mathrm{q}_{\mathrm{h}}^{2}+\delta \mathrm{q}_{\mathrm{h}} \mathrm{q}_{\mathrm{f}}+\mathrm{q}_{\mathrm{f}}^{2} .
$$

As before, it is useful to begin by comparing exporting and FDI in the absence of uncertainty (zero variance). In such an environment it is straightforward to show that home country welfare is unaffected by the foreign firm's location choice as long as the foreign firm faces the same (expected) marginal costs in both countries. If FDI lowers the foreign firm's cost, the foreign firm's price falls with FDI, benefiting home country consumers relative to exporting. 
As a result, a country's attitude towards FDI depends on how closely related the products are. If they are sufficiently differentiated the home firm is not harmed, but the home consumer benefits from lower prices and so welfare increases. We next turn how this result is affected by the presence of cost uncertainty. As before, we start with the case without the learning effect.

\section{A FDI with only correlation effects}

Suppose that the foreign firm chooses exporting. Using (1) in the consumer surplus (13) and taking the expectation yields:

$$
\begin{aligned}
\mathrm{E}\left[\mathrm{CS}^{\mathrm{X}}\right] & =\operatorname{CS}\left(\overline{\mathrm{c}}_{\mathrm{f}}, \overline{\mathrm{c}}_{\mathrm{h}}\right)+\left(4-3_{-}{ }^{2}\right) \sigma_{\mathrm{f}}{ }^{2} / 2_{-}{ }^{2}+\left(4-3_{-}{ }^{2}\right) \sigma_{\mathrm{h}}{ }^{2} / 2_{-}{ }^{2} \\
& =\mathrm{CS}\left(\overline{\mathrm{c}}_{\mathrm{f}}, \overline{\mathrm{c}}_{\mathrm{h}}\right)+\left(4-3_{-}{ }^{2}\right) \sigma^{2} /{ }_{-}^{2}
\end{aligned}
$$

where $\operatorname{CS}\left(\overline{\mathrm{c}}_{\mathrm{f}}, \overline{\mathrm{c}}_{\mathrm{h}}\right)$ is the "mean" consumer surplus, that is consumer surplus if variance equals zero. The convention on the variance terms remains the same as earlier: the subscripts on the variance terms are only to ease comparison as $\sigma_{\mathrm{f}}{ }^{2}=\sigma_{\mathrm{h}}{ }^{2}=\sigma^{2}$, from which results the second equality in (14).

With FDI, home country consumers are no longer affected by the foreign country's shocks but are subject to the correlation of strategies, so the expected consumer surplus is

$$
\mathrm{E}\left[\mathrm{CS}^{\mathrm{FDI}}\right]=\mathrm{CS}\left(\overline{\mathrm{c}}_{\mathrm{h}}, \overline{\mathrm{c}}_{\mathrm{h}}\right)+\sigma_{\mathrm{h}}^{2}(1+\delta) /(2+\delta)^{2} .
$$

A calculation shows that $\mathrm{E}\left[\mathrm{CS}^{\mathrm{FDI}}\right]>\mathrm{E}\left[\mathrm{CS}^{\mathrm{X}}\right]$ if and only if

$$
\sigma^{2}>\left(\overline{\mathrm{c}}_{\mathrm{h}}-\overline{\mathrm{c}}_{\mathrm{f}}\right)\left[\left(4-3 \delta^{2}\right)\left(2-\overline{\mathrm{c}}_{\mathrm{f}}-\overline{\mathrm{c}}_{\mathrm{h}}\right)+2 \delta^{3}\left(2-\overline{\mathrm{c}}_{\mathrm{h}}\right)\right] / 2_{-}^{3} .
$$

Intuitively, expected consumer surplus increases with FDI due to two effects: correlation of strategies, and change in expected cost. The correlation of strategies increases price variability: when a firm's cost is low, so is its rival's, which makes the price even lower. Since consumers choose their quantities after observing the price, they benefit from increased price variability. 
They can enjoy bigger probability of a "sale", and when the price is high, they can always substitute to other products. In addition, FDI occurs only if reduces the foreign firm's expected cost, so the expected cost change always benefits consumers. ${ }^{18}$ We state this formally as

Proposition 3: With only the correlation effect, home country consumers always prefer FDI when the foreign firm chooses FDI.

We now turn to home country welfare. When expected costs in the two countries are equal, FDI hurts the home firm but benefits consumers through the correlation effect. Further, if it lowers the foreign firm's average cost, FDI is more harmful to the home firm but more beneficial to consumers. Therefore, the home country's preference towards FDI is not immediate. The question then is if and when the home country prefers FDI to exporting.

A calculation shows that home country welfare is greater with FDI only if

$$
\sigma^{2}<\left(\overline{\mathrm{c}}_{\mathrm{f}}-\overline{\mathrm{c}}_{\mathrm{h}}\right)\left[2-\overline{\mathrm{c}}_{\mathrm{f}}-2_{-}+\overline{\mathrm{c}}_{\mathrm{h}}\left(2_{-}-1\right)\right] / 2_{-} \text {and } \_<\left(2-\overline{\mathrm{c}}_{\mathrm{f}}-\overline{\mathrm{c}}_{\mathrm{h}}\right) / 2\left(1-\overline{\mathrm{c}}_{\mathrm{h}}\right) .
$$

We then have

\section{Proposition 4: With only correlation effects:}

A. Home country welfare is always greater with exporting if $\delta=1$.

B. If $\delta<1$, then home country welfare is greater with FDI only if there is a cost advantage with FDI, i.e., $\overline{\mathrm{c}}_{\mathrm{f}}>\overline{\mathrm{c}}_{\mathrm{h}}$

Proposition 4A obtains because the second inequality fails at $\delta=1$. Proposition 4B holds because

\footnotetext{
${ }^{18}$ Interestingly, (16) can hold even if $\overline{\mathrm{c}}_{\mathrm{f}}<\overline{\mathrm{c}}_{\mathrm{h}}$; that is, consumers may prefer FDI to exporting even if FDI raises the equilibrium price.
} 
the first inequality fails unless $\overline{\mathrm{c}}_{\mathrm{f}}>\overline{\mathrm{c}}_{\mathrm{h}}$. Put slightly differently, Proposition 4 says that, if $\delta=1$ the home country is worse off with FDI, and if $\delta<1$, it is worse off with FDI if FDI does not reduce cost sufficiently or the products are too close substitutes.

Furthermore, observe that for sufficiently distinct products the home country prefers FDI at zero variance, but as variance increases, the home country's preferences can switch in favor of exporting. Thus, the stochastic nature of the world makes FDI less attractive to the home country.

\section{B FDI with correlation and learning}

We now revert to the setting in which the firms do not learn each other's cost realizations when the foreign firm chose exporting. If the foreign firm exports, then consumers are subject to cost shocks in both countries. Since shocks are uncorrelated across countries, we can use (3) and (9) to express expected consumer surplus as

$$
\mathrm{E}\left[\mathrm{CS}^{\mathrm{X}}\right]=\operatorname{CS}\left(\overline{\mathrm{c}}_{\mathrm{f}}, \overline{\mathrm{c}}_{\mathrm{h}}\right)+\sigma_{\mathrm{f}}^{2} / 8+\sigma_{\mathrm{h}}{ }^{2} / 8
$$

where $\operatorname{CS}\left(\overline{\mathrm{c}}_{\mathrm{f}}, \overline{\mathrm{c}}_{\mathrm{h}}\right)$ is the "mean" consumer surplus. With FDI, home country consumers are no longer affected by the foreign country's shocks but are subject to the correlation of strategies. Thus, expected consumer surplus is the same as in (15).

FDI now affects consumer welfare through learning in addition to the correlation and the expected cost effect, which were discussed in the previous subsection. While the latter two had a positive impact on consumer surplus, as we showed earlier, the firms' learning of the rival's costs hurts consumers by reducing price variability. For example, suppose that, on observing a low cost, a firm produces more, lowering the price. If the rival knows that the firm has a low cost, however, the rival's instinct is to cutting back on production, holding its cost constant. This 
reaction by the rival partially offsets the initial price fall and reduces price variability, hurting consumers.

We show this more formally. A comparison shows that the variance term is smaller in (15) than in (18). Therefore, if the expected costs are equal, consumers are worse off with FDI than with exporting. Since in the absence of the learning effect consumers always prefer FDI to exporting (Proposition 3), this difference in their preferences must be due to the learning effect, and the learning effect must be negative on consumer welfare.

A calculation shows that $\mathrm{E}\left[\mathrm{CS}^{\mathrm{FDI}}\right]>\mathrm{E}\left[\mathrm{CS}^{\mathrm{X}}\right]$ only if

$$
\left.\sigma^{2}<2\left(\overline{\mathrm{c}}_{\mathrm{f}}-\overline{\mathrm{c}}_{\mathrm{h}}\right)\left[\left(4-3 \delta^{2}\right) \overline{\mathrm{c}}_{\mathrm{f}}+\left(1-3 \delta^{2}+2 \delta^{3}\right) \overline{\mathrm{c}}_{\mathrm{h}}-2(1+\delta)\left(2-{ }_{-}\right)^{2}\right)\right]_{-}^{2}(2-)^{2}
$$

Comparing this with the first inequality in (12), we find that (19) holds, whenever the counterpart in (12) holds. In words, we have

\section{Proposition 5: With both correlation and learning effects, home-country consumers always prefer FDI when the foreign firm chooses $F D I$.}

The result that consumers prefer the arrangement that induces learning is reminiscent of some results from the information-sharing literature (e.g., Vives 1984). However, it also contradicts other results (e.g., Shapiro 1986), emphasizing how markedly different the present framework is from that in the information sharing literature even though there is learning here. There are two main reasons for the differences. First, in the information sharing literature, the cost distributions naturally are held constant while here the foreign firm's cost distribution changes according to the location choice it makes. That is, in the information sharing literature the question is whether, given the cost distributions, consumers benefit from the firms learning each 
other's costs, while here the question is whether consumers benefit from the firms learning each other's costs when the firm's cost distributions change. Second, here the firm's location decision changes the type of information (public or private valued), while again, it is natural to assume in the information sharing literature that the type of information remains constant (public-valued in Vives 1984 and private-valued in Shapiro 1986). Since our setting is unique, attempting to derive the welfare implications here by an appeal to the information sharing literature is a misguided endeavor.

Turning to home country welfare, a computation shows that home country welfare is greater with a cost-reducing FDI only if

$$
\begin{gathered}
\sigma^{2}<\left(\overline{\mathrm{c}}_{\mathrm{f}}-\overline{\mathrm{c}}_{\mathrm{h}}\right)\left[2-\overline{\mathrm{c}}_{\mathrm{f}}-2-+\overline{\mathrm{c}}_{\mathrm{h}}(2-1)\right] /\left(2-\_\right) \\
\text {and } \_\left(2-\overline{\mathrm{c}}_{\mathrm{f}}-\overline{\mathrm{c}}_{\mathrm{h}}\right) / 2\left(1-\overline{\mathrm{c}}_{\mathrm{h}}\right) .
\end{gathered}
$$

This is similar to (17), implying that in the presence of the learning effect Proposition 4 holds. We state this formally as

\section{Proposition 6: With both correlation and learning effects Proposition 4 still holds:}

\section{A. Home country welfare is always greater with exporting if $\delta=1$.}

B. If $\delta<1$, then home country welfare is greater with FDI only if there is a cost advantage with FDI, i.e., $\overline{\mathrm{c}}_{\mathrm{f}}>\overline{\mathrm{c}}_{\mathrm{h}}$

Thus, if the products are perfect substitutes $(\delta=1)$, FDI always lowers home country welfare even if it lowers prices, benefiting consumers, whether or not FDI induces the learning effect. Therefore, the home country always opposes FDI with perfect substitutes - the classic model. When the products are differentiated, the conditions under which the home country 
prefers FDI differ, depending on the presence of the learning effect. ${ }^{19}$ Comparing (17) with (20) we find that without learning the home country is more likely to find FDI beneficial. We formalize this finding as

Corollary: Suppose that $\_\left(2-\overline{\mathrm{c}}_{\mathrm{f}}-\overline{\mathrm{c}}_{\mathrm{h}}\right) / 2\left(1-\overline{\mathrm{c}}_{\mathrm{h}}\right)$. Then cost-reducing FDI is more likely to raise home country welfare without learning than with learning.

The difference between the modeling here and that in the information-sharing literature is even clearer with this result. While learning increases welfare in Shapiro (1986) with privatevalued cost information and in Vives (1984) with public-valued cost information, here, by the above corollary, learning reduces welfare because the learning occurs with a change of the type of information - a possibility not considered in the information sharing literature.

\section{Price competition}

Until now we have not consider how price competition may affect the results. While in the literature the results are often strikingly sensitive to the type of competition, here the general results remain essentially the same in price competition although there are some subtle differences. To begin with, the correlation and learning effects still appear in price competition. The correlation effect is negative for the firm as before, but now the learning effect is also negative. This can be intuitively understood by the following example. Suppose that the rival draws a higher-than-average cost and raises its price, benefiting the firm at a given price. However, learning that the rival sets a higher price induces the firm to raise its own price, which makes the profit function less convex and reduces the expected profit.

\footnotetext{
${ }^{19}$ The conditions on product differentiation are identical, but those on variance differ.
} 
Now, with the learning effect and the correlation effect working together against FDI, it takes an even greater cost advantage to induce FDI than in quantity competition (see Proposition 2). As a result, FDI is less likely to occur in a given environment (i.e., for the same cost difference and distributions), but when it does, it must be because FDI reduces cost significantly, which creates a large benefit for home consumers. ${ }^{20}$ The home firm on the other hand is made worse off by FDI because now FDI induces a larger price drop but also because it generates a learning effect, which reduces the average profit in price competition, as discussed above. Home country welfare can still be higher with FDI precisely because FDI induces a substantial price reduction. These results are in essence the same as with quantity competition. Given the outline of our derivations for the quantity case, deriving these results is straightforward (if tedious) and so omitted.

\section{Conclusions}

A remarkable rise in multinational activity has spawned a growing interest in explaining why some firms choose foreign investment over exporting. This paper investigates the role of country-specific cost uncertainty in a firm's choice between exporting and FDI. We find two new effects that FDI induces in the presence of country-specific cost uncertainty: the correlation and the learning effect. The correlation effect occurs because FDI expose the firms to the identical country-specific cost shocks, which results in the firms' strategies being correlated. It therefore reduces the firms' expected profit and hence serves as a barrier to FDI.

The learning effect arises because, when exposed to common shocks, the firms can learn about each other's cost realizations by observing their own. The learning effect makes FDI more attractive relative to exporting for both the foreign and the home firm. The net impact is that FDI

\footnotetext{
20 This is despite the fact that with price competition the correlation effect is negative for consumers.
} 
reduces the firms' expected profit. Thus, the foreign firm does not choose FDI unless it gives the firm a substantial cost advantage in the form of lowering the expected cost. Then, when there is FDI the home firm is always worse off.

Turning to home country consumers, we find the effects on consumers reversed. While correlation of strategies harms the firms, it benefits consumers; while learning is good for the firms, it hurts consumers. However, when FDI generates both the correlation and the learning effect, it usually harms consumers. But, when FDI hurts the consumers, it hurts the foreign firm more. Therefore, whenever the foreign firm chooses FDI, the home consumers benefit from it. Due to the conflict between the home firm and home consumers as regards preference over FDI the effect of FDI on home country welfare depends on other factors such as the size of variance and the degree of product differentiability.

One definite conclusion we find is that a reduction in country-specific variance makes FDI relatively more attractive to the home country. This has the following implication on globalization: to the extent that it homogenizes economies and hence diminishes the country specificity of shocks, globalization fosters FDI. If it is FDI that homogenizes economies (e.g., by having common input sources), then current FDI encourages future FDI - a cascading effect.

On the other hand, we get another view of globalization by comparing the two versions of the model. Specifically, if globalization implies faster information flows across nations so each firm come to learn its rival's costs without being in the same locale, then since the learning effect is positive, its loss reduces the expected profit from FDI, thereby increasing the firms' preference for exporting.

Although our setting is simple, with one firm in each country, the insights here can be applied to many other settings. For example, consider an alternate environment in which both 
firms are located in the foreign developed country (North) and are choosing whether to invest in a developing country (South). For simplicity, assume no Southern firms. In this environment, if costs are sufficiently close (but not necessarily equal), both firms would prefer that one firm chooses FDI while the other continues to export over both of them exporting. That is, neither both choosing FDI nor both choosing to export is an equilibrium, as each firm would have an incentive to deviate. If expected costs are sufficiently close, by proposition 1, neither firm would have an incentive to deviate if one chooses FDI and the other exports. Thus, we do not expect to see foreign investment cascades unless home production costs are sufficiently lower.

It can be easily seen then that the results can be applied even further: for example, the firms need not even consider locating in the South but rather a third country. Likewise it is straightforward to show that if a third firm is added then all three would want to locate in separate countries if expected costs are sufficiently close. Interestingly, a firm benefits from its rivals locating in the same country.

As with the firms, the result of proposition 3 can easily be applied beyond our setting. Returning to the earlier example of two Northern firms choosing whether to invest or to continue exporting, Southern consumers prefer that the two firms continue to FDI does not have too large of a marginal cost advantage. That is, now consumers are against one foreign firm choosing FDI because it reduces the correlation effect (unless both firms choose FDI). Likewise, Southern consumers are against the foreign firms choosing FDI in third countries as this reduces the correlation effect. We leave such formalization and other extensions to future research. 


\section{References}

Caves, R. E., 1996, Multinational enterprise and economic analysis, $2^{\text {nd }}$ edition, London: Cambridge University Press.

Creane, A., 1998, Risk and revelation: changing the value of information, Economica 65 (May) 247-261.

Creane, A. and K. Miyagiwa, 2007, Foreign direct investment, joint ventures and mergers: learning costs through propinquity, unpublished working paper.

Cushman, D. O., 1985, Real exchange rate risk, expectations, and the level of investment, Review of Economics and Statistics 67, 297-308

Ethier, W. J., 1986, The multinational firm, Quarterly Journal of Economics 101, 805-834

Gal-or, E., 1985, Information sharing in oligopoly, Econometrica 53, 329-343

Gal-Or, E., 1986, Information Transmission - Cournot and Bertrand Equilibrium, Review of Economic Studies 53, 85-92.

Goldberg, L. S., and Kolstad, C. D., 1995, Foreign direct investment, exchange rate variability and demand uncertainty, International Economic Review 36, 855-73

Helpman, E., 1984, A simple theory of international trade with multinational corporations, Journal of Political Economy 92, 451-471.

Helpman, E.; Melitz, M. J.; Yeaple, S. R., 2004, Export versus FDI with heterogeneous firms, American Economic Review 94, 300-316

Horstmann, I. J., and Markusen, J. R.; 1992, Endogenous market structures in international trade (natura facit saltum), Journal of International Economics, 32, vol. 1, 109-129

Markusen, J. R., 1984, Multi-national multi-plant economies and the gains from trade, Journal of International Economics 16, 205-226.

Markusen, J. R.; 1995, The boundaries of multinational enterprises and the theory of 
international trade. Journal of Economic Perspectives, Vol. 9, No. 2, Spring, 169-189

Markusen, J. R., 2003, Multinational firms and the theory of international trade; Cambridge, MIT Press.

Raith, M., 1996, A general model of information sharing in oligopoly, Journal of Economic Theory 71, 260-288.

Qiu L. D. and W. Zhou, 2006, International mergers: incentives and welfare, Journal of International Economics 68, 38-58.

Salant, S., S. Switzer, and R. Reynolds, 1983, Losses Due to Merger: The Effects of an Exogenous Change in Industry Structure on Cournot-Nash Equilibrium, Quarterly Journal of Economics, 48, 185-200

Shapiro, C., 1986, Exchange of Cost Information in Oligopoly, Review of Economic Studies, Vol. 53, No. 3 (Jul., 1986), 433-446.

Sung, H., and Lapan, H.; 2000, Strategic direct investment and exchange-rate uncertainty, International Economic Review 41 (May), 411-423

Viaene, J-M., and I. Zilcha, 1998, The behavior of competitive exporting firms under multiple uncertainty, International Economic Review, 39(3):pp. 591-609.

Vives, X., 1984, Duopoly information equilibriurm: Cournot and Bertrand, Journal of Economic Theory 34, 71-94

Vives, X. 1990. Trade association disclosure rules, incentives to disclose information and welfare. Rand Journal of Economics 21(3): 409-30. 